Background With advance in perinatal care, knowledge, experience and technology:

The outcome of the extreme preterm infants ( $<30$ weeks gestation, and $<1000 \mathrm{~g}$ has been upturning; King Faisal Sp. Hospital, we are lacking data for parents counseling, and bench mark for the unit.

Method Retrospective study to evaluate the short outcome experience results for extreme preterm infants whom inborn or transferred to our unit, within 2 weeks after birth, over 12 years. Infants with multiple congenital anomalies, or transferred with complications excluded.

SPSS version 20 to analyze the data collected in case report form (CRF). Several variables studied, the mortality rate and hospital stay were calculated.

Results 324 files studied 92 (28\%) met inclusion criteria, 232 excluded 71\%, 92 infants, (50\% each males and females); All developed RDS (100) Mortality (10/92) 11\%; ROP(24/92) 16\%; NEC(6/92)7\%; SEPSIS(40/92) 43\% G-ve was 32\%, G+ ve 23\%; PNUMONIA(5/92)5\%; PVL(3/92) 3\%; BPD(16/92) 17\%; IVH (17/92) 18\%; MENINGITIES(2/92) 2\%; PDA(85/92) 92\%, 64\% self closed, 9\% Indomethacin, 6\% ibuprofen, 21\% required surgery; length of stay (LOS) mean of 64 days.

Conclusion and recommendation Results comparable to results reported by National Institute of Child Health and Human Development (NICHHD). Extreme preterm infants should be delivered or transferred within one week to a tertiary care facilities for best outcome.

\section{P0-0637 DIABETES IN PREGNANCY AND THE RISK OF SEVERE PERINATAL COMPLICATIONS: DATA FROM THE FRENCH POPULATION IN 2011}

${ }^{1} \mathrm{C}$ Billionnet, ${ }^{1} \mathrm{~A}$ Weill, ${ }^{2} \mathrm{U}$ Simeoni, ${ }^{1} \mathrm{P}$ Ricordeau, ${ }^{3} \mathrm{~F}$ Alla, ${ }^{4} \mathrm{~S}$ Jacqueminet, ${ }^{4} \mathrm{~A}$ Hartemann, ${ }^{5}$ D Mitanchez. 'Département d'études en Santé Publique, Caisse Nationale d'Assurance Maladie, Paris, France; ${ }^{2}$ Service de Néonatologie UMR608 INSERM, Assistance Publique - Hôpitaux de Marseille, Marseille, France; ${ }^{3}$ Direction Générale, Caisse Nationale d'Assurance Maladie, Paris, France; ${ }^{4}$ Service de Diabétologie Sorbonne Universités UPMC Univ Paris 06, Hôpital Pitié Salpêtrière APHP, Paris, France; ${ }^{5}$ Service de Néonatologie Sorbonne Universités UPMC Univ Paris 06, Hôpital Armand-Trousseau APHP, Paris, France

\subsection{6/archdischild-2014-307384.1278}

We evaluated the risks of severe perinatal complications according to the type of maternal diabetes from the French birth cohort in 2011.

Method Data were obtained from the PMSI (medical Information system program) and the SNIIRAM (inter-regimens national system of information) of the French health insurance. All the childbirths and the terminations of pregnancy (TOP) after 22 weeks were selected. The mother's diabetic status was determined by an algorithm based on the consumption of anti diabetics and hospitalisation diagnoses before and during pregnancy. An identifier in the PMSI links mothers and children, thus enabling analyses of associations between the diabetic status and complications in neonates.

Results 806579 childbirths/TOP > 22 weeks were identified in the PMSI. Mother- child chaining was obtained for 474614 births. In the case of type 1 and type 2 diabetes, the risk was respectively increased for the following complications (OR adjusted on mother age [95\%CI]): perinatal death $(2.2$ [1.4-3.4] and $3.0[2.2-4.1])$, perinatal asphyxia $(3.3[2.2-5.1]$ and 2.5
[1.6-3.7]), respiratory distress syndrome (OR adjusted on mother age and gestational age: 2.6 [2.0-3.4] and 1.9 [1.5-2.5]), brachial plexus trauma and/or collarbone fractures in cases of vaginal delivery (8.5 [4.9-14.8] and 2.9 [1.5-5.9]), cardiac malformations (4.4 [3.0-6.5] and 3.2 [2.2-4.7]). In cases of GD, the risk was not increased for these complications compared to the population without diabetes, except for the respiratory distress syndrome (1.2 [1.1-1.3]).

Conclusion The risk of severe perinatal complications remains high in case of pregestational diabetes.

\section{P0-0638 USEFULNESS OF CLINICAL RISK INDEX FOR BABIES, SCORE FOR NEONATAL ACUTE PHYSIOLOGY AND SNAPPE II IN PREDICTING HOSPITAL MORTALITY IN PRETERM WITH LOW BIRTH WEIGHT}

M Muñoz-Garcia, MC Martínez-Padilla, L Millán-Miralles, C Santiago-Gutiérrez, I de la Cruz-Moreno. Department of Pediatrics, Complejo Hospitalario de Jaén, Jaén, Spain

\subsection{6/archdischild-2014-307384.1279}

Currently, there is an increased rate of prematurity. The use of risk score calculators is a simple and easy tool to implement in neonatal units. The aim of our study was to evaluate the usefulness of CRIB-II, SNAP-II and SNAPPE-II scores in predicting hospital mortality in preterm infants with low birth weight.

Methods A total of 81 preterm infants with low birth weight and $\leq 32$ weeks of gestation were evaluated. Morbidity and mortality data were recorded and CRIB-II, SNAP-II and SNAPPE-II were analysed. Discriminative value was evaluated by calculating the ROC curve.

Results The overall mortality was $17.3 \%$. The average score CRIB-II, SNAP-II and SNAPPE-II was higher for preterm died versus those who survived $(13.7 \pm 4.1$ vs. $5.8 \pm 3.2, \mathrm{p}<0.001$; $33.8 \pm 16$ vs. $12 \pm 10, \mathrm{p}<0.001$ y $52.7 \pm 15.9$ vs. $15.9 \pm 13$, $\mathrm{p}<0.001$, respectively). CRIB II score showed an area under the curve of 0.925 (95\% CI 0.859 to 0.991 ), $\mathrm{p}<0.001$. A cutoff of 8.5 had a sensitivity $92.9 \%$ and a specificity $80.6 \%$ for predicting mortality. The SNAP-II score provided an area under the curve of 0.863 (95\% CI 0.758 to 0.968$) \mathrm{p}<0.001$ and a cutoff of 20.5 presented a sensitivity $78.6 \%$ and a specificity $83.6 \%$. The SNAPPE II score showed an area under the curve of 0.925 (95\% CI 0.859 to 0.991$), \mathrm{p}<0.001$. A cutoff of 25.5 presented a sensitivity $85.7 \%$ and a specificity $82.1 \%$. The correlation was higher for CRIB-II and SNAPPE-II, $\mathrm{r}=0.766, \mathrm{p}=$ 0.001 .

Conclusions The use of SNAP-II, SNAPPE-II and CRIB-II scores has a high ability to predict neonatal hospital mortality.

\section{PO-0639 IMPACT OF NEONATAL MORBIDITIES ON CLINICAL OUTCOME AND PREDICTORS OF MORTALITY IN PRETERM INFANTS WITH LOW BIRTH WEIGH}

M Muñoz-Garcia, L Millán-Miralles, C Santiago-Gutiérrez, MC Martínez-Padilla, J de la Cruz-Moreno. Department of Pediatrics, Complejo Hospitalario de Jaén, Jaén, Spain

\subsection{6/archdischild-2014-307384.1280}

Background Advances in perinatal care have made it possible to improve survival of infants with low birth weight. The aims of 